\title{
Simulation and Analysis of 4-D Airspace Closures due to Commercial Space Operations: Impacts on Airlines and General Aviation
}

Janet K. Tinoco

Embry-Riddle Aeronautical University, tinocoj@erau.edu

Noah D. Eudy

Embry-Riddle Aeronautical University, eudyn@my.erau.edu

Maxwell Cannon

Embry-Riddle Aeronautical University, cannonm6@my.erau.edu

Follow this and additional works at: https://commons.erau.edu/jaaer

Part of the Aerospace Engineering Commons, and the Management and Operations Commons

\section{Scholarly Commons Citation}

Tinoco, J. K., Eudy, N. D., \& Cannon, M. (2020). Simulation and Analysis of 4-D Airspace Closures due to Commercial Space Operations: Impacts on Airlines and General Aviation. Journal of Aviation/Aerospace Education \& Research, 29(3). https://doi.org/10.15394/jaaer.2020.1853

This Article is brought to you for free and open access by the Journals at Scholarly Commons. It has been accepted for inclusion in Journal of Aviation/Aerospace Education \& Research by an authorized administrator of Scholarly Commons. For more information, please contact commons@erau.edu. 


\section{Introduction}

The number of commercial spaceports in the United States (U.S.) is growing ${ }^{1}$ as both public and private entities are examining commercialized space transportation as a means of economic growth (Tinoco, Yu, Howard, \& Stilwell, 2020a). Stakeholders that lie outside the space industry, such as those in the nation's aviation sector, are voicing concern over the negative effects space operations have on their own operations, as commercial space launch and return activities become the norm rather than the exception (e.g., Air Line Pilots Association [ALPA], 2019).

Clear and available 4-D airspace in volume and time is a key component of both the aviation and commercial space eco-systems. The U.S. Federal Aviation Administration (FAA) handles on average more than 16.1 million flights, 1 billion U.S. passengers, and 43.3 billion pounds of cargo yearly (Federal Aviation Administration [FAA], 2019). Additionally, data on general aviation (GA) show more than 25.2 million flight hours (FAA, 2019) with approximately $65 \%$ of flights devoted to business and public transportation (Aircraft Owners and Pilots Association [AOPA], 2019). Meanwhile, space launch cadence is increasing. Cecil Air and Space Port in Jacksonville, Florida forecasts 52 horizontal launches per year (Jacksonville Aviation Authority, 2014), averaging one launch per week. Cape Canaveral Air Force Station (CCAFS) in Cape Canaveral, Florida is building to an anticipated 48 vertical launches per year (Gebhardt, 2017). With this level of activity, airspace use and closures from commercial space operations have the potential to negatively impact the aviation economy.

\footnotetext{
${ }^{1}$ To date, there are 12 active commercial spaceport operator licenses in the U.S. Each license corresponds to a spaceport site for commercial activity (FAA, 2020). In addition, there are active National Aeronautics and Space Administration (NASA) and government military launch sites, most notably NASA Kennedy Space Center (KSC) and NASA Wallops Flight Facility, Vandenberg Air Force Base, and Cape Canaveral Air Force Station (CCAFS).
} 
Clearly, pilots must follow air traffic rules to ensure safety of air and NAS efficiency. While there is significant flexibility for aircraft to alter their planned flight paths if necessary, it is nearly impossible for rockets, once launched, to change trajectory to avoid aviation traffic. Their planned flight trajectory, date, and time of launch are carefully scripted based on the destination point in space. Additional variables, such as poor weather, can lead to smaller and smaller windows of opportunity for launch.

Besides vertical launch activities, reusable launch vehicles (RLVs), rocket boosters, and reusable spaceplanes are, or will be, returning from space to land either vertically on drone ships, landing pads, land horizontally on runways, or splash down in the ocean (Tinoco, Yu, Howard, \& Stilwell, 2020b). With the pending completion and future first mission of Sierra Nevada Corporation's Dream Chaser, the return of the vehicle from space will require 4-D corridors of open airspace and horizontal landing runways of sufficient length and capability to accommodate the glider's return from lower Earth orbit (LEO) (Tinoco, Yu, Howard, \& Stilwell, 2020c).

For both launch and landing, aviation traffic is either re-routed, held on the ground, postponed, and/or cancelled, resulting in additional costs for the airlines and GA. In the past, these national airspace system (NAS) users accepted the impacts of government space activities on business operations. However, with the burgeoning commercial space industry, commercial entities are vying for airspace with other commercial entities, resulting in growing conflicts between these competing interests. A critical issue for the continued growth and development of both sectors is resolving airspace integration of all stakeholder activities in a safe, fair, effective, and efficient manner (Tinoco et al., 2019).

Currently, there is limited research on the integration of commercial space operations into the NAS that focuses on impacts to the airlines and in finding solutions (see Tinoco et al., 2019; 
Tinoco et al., 2020; Colvin \& Alonso, 2015). Further, we know of no published research that examines impacts to international carriers flying into and out of the NAS or addresses impacts to GA. Thus, our exploratory study builds on prior efforts with the following research questions: How many flights are potentially impacted by launch and re-entry activities during a given time and location? Of these flights, how many are international carriers and how many are GA?

Using simulation techniques, we assess the impacts to aviation due to launch/landing activities at Cape Canaveral Spaceport ${ }^{2}$ (CCS) by developing two baselines models using historical records for airspace closures: one model examines impacts due to SpaceX Falcon vertical launch operations and the other examines impacts due to horizontal landings at Kennedy Space Center (KSC). Using NASA Future ATM Concept Evaluation Tool (FACET) simulation software and real airspace traffic data provided by NASA, simulations were conducted, and impacts analyzed.

\section{Background}

Most of the published literature on the integration of space traffic into airspace focuses on risk analysis, hazard analysis, and air traffic control integration tools. With respect to airspace and air traffic, there is a single layer of literature available that is limited in nature on aviation impacts. A summary of relevant research is displayed in Table 1. ALPA $(2018,2019)$ reports 563 flights may have been impacted as a result of one SpaceX Heavy launch out of CCS. Young and Kee (2014) show that a Falcon 9 launch caused 25 to 84 nautical miles (nm) in extra flight distances and up to 23 minutes in delays. Conversely, it is noted that re-entry of the Dragon capsule into the Pacific Ocean resulted in minimal impact to commercial flights to and from Hawaii and Australia. Finally, Tinoco et al. (2020) examine various scenarios using predictive

\footnotetext{
${ }^{2}$ Space Florida refers to the combined entities of NASA KSC and the CCAFS as the Cape Canaveral Spaceport. CCS currently is the busiest spaceport in the U.S. and in the world.
} 
fast-time simulation modeling, focusing on Cecil Air and Space Port in Jacksonville, Florida. Their results indicate that currently planned airspace closures in time and space impact 114 flights, including those of domestic and international passenger carrier and cargo. These impacts were the result of one horizontal launch occurring at 7 a.m. on a weekday. (For specifics on allowed launch times, see Letter of Agreement, Operations at the Cecil Spaceport at Cecil Field, Jacksonville, Florida, dated October 1, 2009.)

Although there was no research found on impacts to GA, a review of NASA KSC media releases suggests that GA operations are typically prohibited within a 30 to $40 \mathrm{~nm}$ radius of the launch area from the surface to 18,000 feet (e.g., National Aeronautics and Space Administration [NASA] 2005; NASA, 2020). Five GA airports are specifically identified in these releases as being affected and include Space Coast Regional Airport and Arthur Dunn Airpark in Titusville, Florida; Merritt Island Airport in Merritt Island, Florida; Rockledge Airpark, Rockledge, Florida; and Massey Ranch, Edgewater, Florida. Clearly temporary suspension of GA operations at these airports can negatively impact smaller general aviation companies, such as flight schools, fixedbase operators (FBOs), and aircraft rental businesses in terms of lost revenues and increased costs. 
Table 1

Summary of Selected Literature on Airspace Integration

\begin{tabular}{|c|c|}
\hline Source & Method/Results \\
\hline $\begin{array}{l}\text { Air Line Pilots } \\
\text { Association (ALPA) } \\
(2018,2019)\end{array}$ & $\begin{array}{l}\text { Provides an overview of impacts for airlines due to space launch } \\
\text { activities. }\end{array}$ \\
\hline $\begin{array}{l}\text { Colvin \& Alonso } \\
(2015)\end{array}$ & $\begin{array}{l}\text { Proposes a new class of hazard area for space launch and re-entry, } \\
\text { termed as compact envelopes that are "dynamic in time, contour in } \\
\text { space as a function of altitude". }\end{array}$ \\
\hline $\begin{array}{l}\text { Larson, Carbon, \& } \\
\text { Murray (2012) }\end{array}$ & $\begin{array}{l}\text { Describes the development of FAA's Shuttle Hazard Area for Aircraft } \\
\text { Calculator (SHAAC). }\end{array}$ \\
\hline Murray (2008) & $\begin{array}{l}\text { Focuses on horizontal launch and landings of space craft using } \\
\text { separation distances. }\end{array}$ \\
\hline $\begin{array}{l}\text { Murray \& Mitchell } \\
\text { (2010) }\end{array}$ & $\begin{array}{l}\text { Provides lessons learned on air traffic impacts due to NASA Space } \\
\text { Shuttle landings at KSC. }\end{array}$ \\
\hline $\begin{array}{l}\text { Srivastava, St. Clair, } \\
\& \text { Pan }(2018)\end{array}$ & $\begin{array}{l}\text { Proposes a two-step approach to estimate the impact of a future space } \\
\text { launch or reentry on airspace in terms of extra flight distances and } \\
\text { delays. }\end{array}$ \\
\hline $\begin{array}{l}\text { Tinoco et al. (2019, } \\
\text { 2020) }\end{array}$ & $\begin{array}{l}\text { Analyzes impacts to airlines due to space operations at Cecil Spaceport, } \\
\text { Jacksonville, FL. Solutions to airspace integration analyzed with RLV } \\
\text { and spaceplane treated as aircraft. }\end{array}$ \\
\hline $\begin{array}{l}\text { Young \& Kee } \\
(2014)\end{array}$ & $\begin{array}{l}\text { Performs statistical analysis of impacts of blocking airspace during } \\
\text { SpaceX Falcon 9's launch from Cape Canaveral (March 1, 2013); re- } \\
\text { entry of Dragon capsule in the Pacific Ocean (March 26, 2013). }\end{array}$ \\
\hline
\end{tabular}

With respect to horizontal landing operations, Murray and Mitchell (2010) study impacts to airspace based on shuttle landing corridors of varying widths. For a landing at KSC, they found that within a 60-minute period during the late morning, the number of traffic conflicts varied from 159 to 195 for a corridor width of $20 \mathrm{~nm}$ to $50 \mathrm{~nm}$, measured from centerline to the outer edge in a perpendicular fashion. If each conflict represents one unique flight with only one flight rerouted, then up to 195 flights were impacted. 
Figure 1 illustrates the space shuttle orbiter (STS-133) re-entry ground path. If a corridor of $25 \mathrm{~nm}$ to $50 \mathrm{~nm}$ in width is created like the aforementioned study, a number of major airports in Florida will be impacted, further highlighting the implications of airspace closures and restrictions on the NAS.

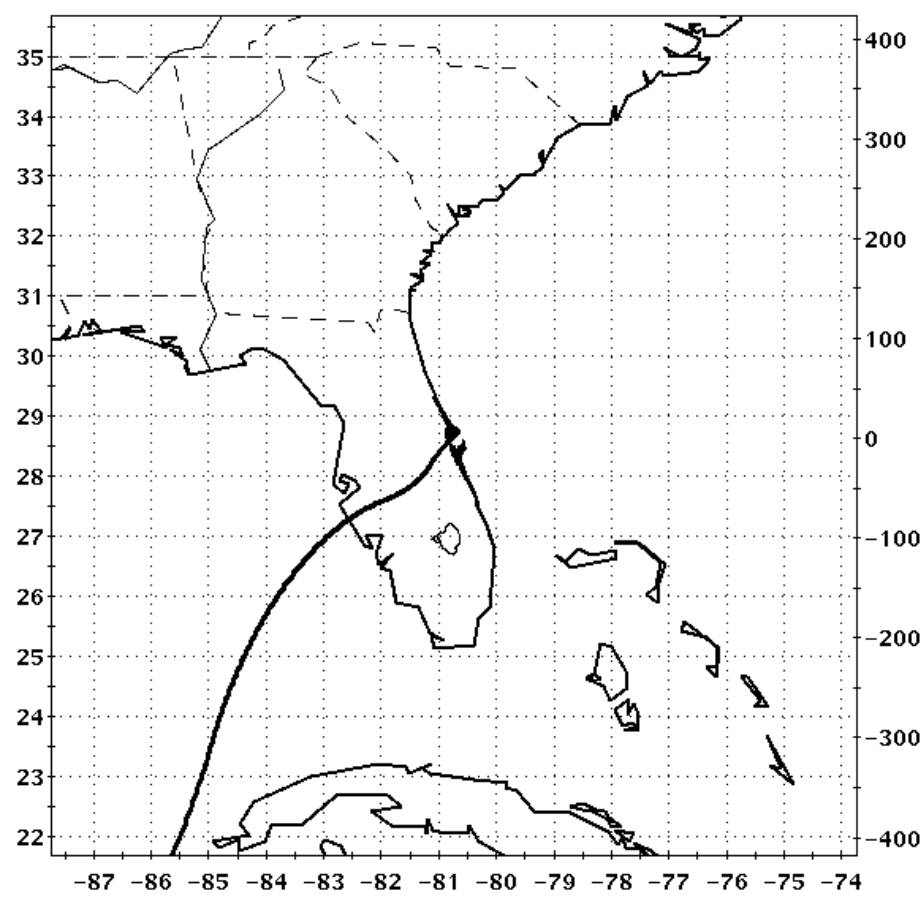

Figure 1. STS-133 orbiter mid-range ground path on return. Reprinted from NASA - STS-133 Landing Ground Tracks, In NASA Shuttle Missions, 2011, March 7. Retrieved August 25, 2020, from https://www.nasa.gov/mission_pages/shuttle/shuttlemissions/sts133/news/landing.html

\section{Methodology}

Our methodology was divided into two phases. The first phase included understanding the baseline air traffic operations over Florida and down the Eastern seaboard of the U.S., representing the existing NAS conditions without space launch/landing activities. Our flight database was that of real air traffic on March 30, 2016. This date had no unusual weather conditions and was a "no launch" date for CCS, which provided a sound baseline for the simulations. The flight database was provided by NASA AMES for use with the simulation 
software, NASA FACET version 19.0 with NAS (National Airspace System) Constraint Evaluation and Notification Tool (NASCENT) version $19.03^{3}$.

In the second phase, we examined the impacts of closed airspace due to launching/landing activities on this air traffic. Using the FAA historical Notice to Airmen (NOTAM) ${ }^{4}$ database (https://notams.aim.faa.gov/notamSearch/nsapp.html\#/), we identified relevant NOTAMs for both launch and landing for the Miami (ZMA) Air Route Traffic Control Center (ARTCC) and identified airspace closures for the Falcon Heavy (one) and SpaceX Falcon (eight) in 2019, the last seven Space Shuttle orbiter landings, and one X-37B landing.

After recording this information, key commonalities were recognized between the airspace closed, time of day, and the length of time it was closed. These commonalities were then used to set the airspace closures for the simulation. For the launch scenario, we chose to concentrate on the SpaceX Falcon 9 launches, thus simulating closures from 00:30 to 04:52 Zulu (total time of 4 hours and 22 minutes) with the most common airspace closures of R2933, R2934, W497A, W137F, and W137G. Refer to Figures 2a and 2b for illustration of these areas. For the horizontal landings, we chose to simulate airspace closures of R2932, R2933, R2934, R2935 and portions of W158A, W158C, and W497A for a period of 4 hours and 20 minutes. A $35 \mathrm{~nm}$ arc centered at latitude $283703 \mathrm{~N}$ and longitude $803647 \mathrm{~W}$ was also included in the airspace closures for every landing. This arc encompassed R2932, R2933, R2934 and portions of W158A, W158C, and W497A. Along with these airspace closures, NOTAMs

\footnotetext{
${ }^{3}$ NASA FACET is a free software platform available from NASA through a use agreement. It was chosen based on cost and ease of use compared to other platforms that were available. Total Airspace and Airport Modeling (TAAM) program by Jeppesen was chosen as the back-up platform.

${ }^{4}$ As all space vehicles create safety hazards as they pass through the NAS, the FAA issues temporary flight restrictions (TFRs) and defines Special Use Airspaces (SUAs), informing pilots which hazard areas to avoid and when, in NOTAMs. The SUA outlines the area which is closed to air traffic temporarily. This can be from Earth's surface to unlimited altitude, depending on the project hazard area. For launch operations, air traffic control (ATC) routes aircraft westward over the peninsula of Florida around Cape Canaveral or provides other instructions, as necessary. For the Orbiter, the NOTAM was listed as Space Shuttle Landing Operations Advisory.
} 
identified a hazard "corridor" with a width of $25 \mathrm{~nm}$ on each side of the center line. Typically, this unique corridor was closed for approximately 35 minutes on approach to the KSC Shuttle Landing Facility ${ }^{5}$. Note that due to some limitations of the software, the researchers were unable to run simulations with this corridor.
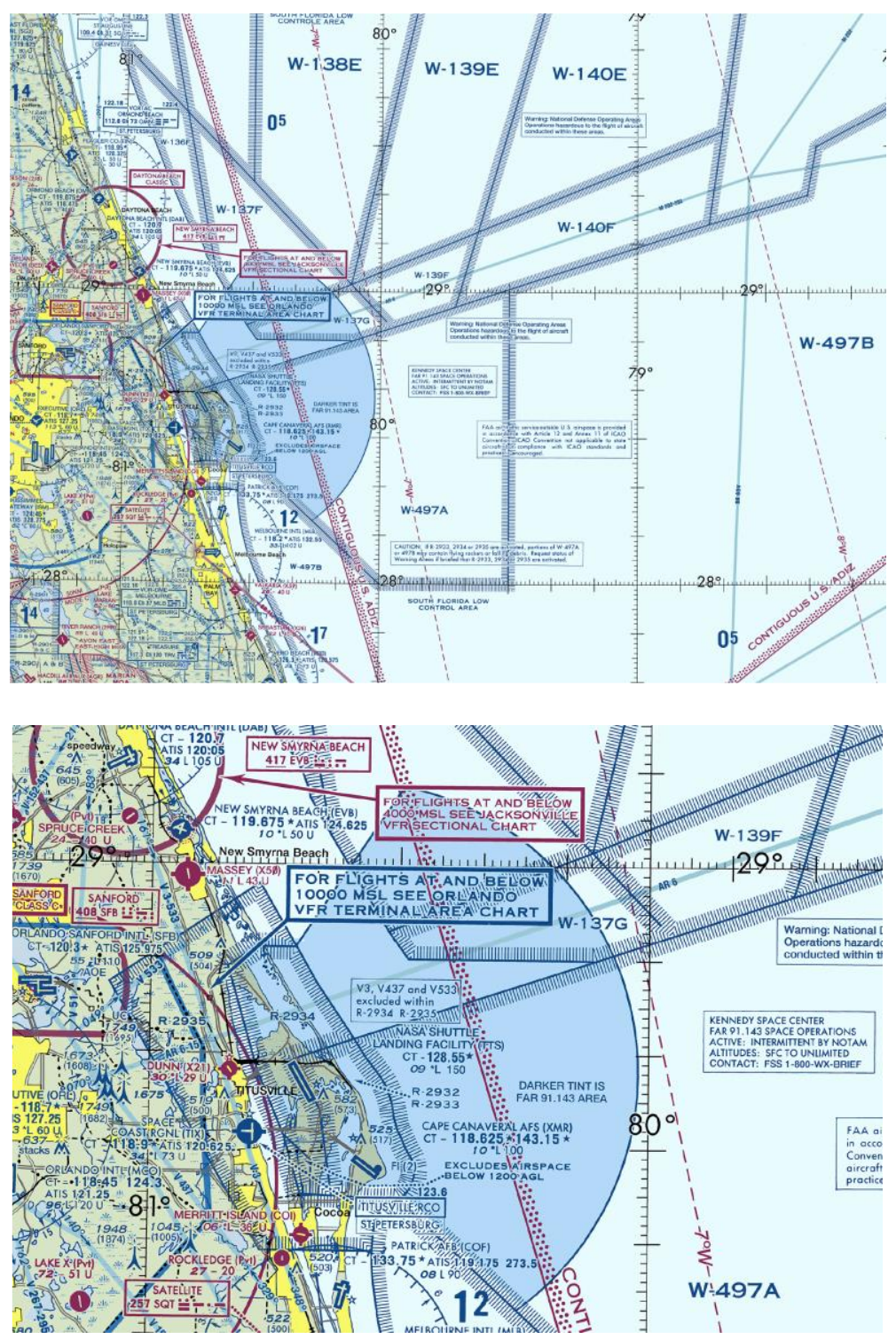

Figures $2 a$ and $2 b$. Aeronautical sectional chart illustrating airspace restricted and warning area boundaries with broader view (a) and close-up (b) (FAA, 2015).

Results

\footnotetext{
${ }^{5}$ Also referred to as the Launch Landing Facility (LLF) operated by Space Florida.
} 
Table 2 outlines the closure times and areas closed, as well as impacts to air traffic. For the Falcon 9 launches, 21 flights were affected, including seven Jet Blue (A320), three United Airlines (B738, B739, ALOR1), two Southwest Airlines (B733, B737), two Delta Airlines (MD88), two American Airlines (A321, B738), one Virgin Atlantic (B744), one Air Canada (ALOR1), one Spirit (A320), one FlexJet (C130), and one flight of unknown affiliation. (Note that returned landing of boosters at CCS would have been within the closure time.) Most of these flights included either Orlando International Airport or Fort Lauderdale-Hollywood International Airport as their destination. Although most of the impacted commercial flights were of domestic airlines, several were of international carriers. Thus, the negative impact of U.S. commercial space activities on airlines goes beyond U.S. carriers.

Table 2

Scenario, Airspace Closure Area and Time, and Impacted Flights

\begin{tabular}{llll}
\hline $\begin{array}{l}\text { Launch/Landing } \\
\text { Scenarios }\end{array}$ & $\begin{array}{l}\text { Closure Time } \\
(\text { Zulu })\end{array}$ & $\begin{array}{l}\text { Area Closed (See } \\
\text { Figure 1) }\end{array}$ & \# of Flights Impacted \\
\hline Launch (Falcon 9) & $00: 30-04: 52$ & $\begin{array}{l}\text { R2933, R2934, } \\
\text { W497A, W137F, }\end{array}$ & 21 flights \\
& & W137G, no arc & \\
Shuttle Landing & $03: 25-07: 45$ & $\begin{array}{l}\text { R2932, R2933, } \\
\text { R2934, R2935, } \\
\text { W158a, W158c, with } \\
\text { arc (no corridor) }\end{array}$ & $\begin{array}{l}\text { commercial airlines } \\
\text { and GA) }\end{array}$ \\
\hline
\end{tabular}

For the space shuttle orbiter landings, 12 flights were affected by the closures, including three Jet Blue (A320), one Southwest Airlines (B737), one American Airlines (A320), one United Airlines (B738), one British Airways (B744), one Allegiant Air (A320), and four GA. The latter represents $33 \%$ of the total number of impacted flights. Additional analyses revealed that there were varying levels of impact whereby some flights barely entered the SUA while 
others were in the SUA for longer periods of time for an average time of 5.5 minutes as shown in Table 3. If the $25 \mathrm{~nm}$ corridor had been included in our model, the number of flights impacted would have been much greater thus the research is not worst case. Most of the impacted flights included Fort Lauderdale-Hollywood International Airport as their destination; however, the British Airways flight was from Aeropuerto Internacional Benito Juarez, Mexico City to London Heathrow.

Table 3

Aircraft that Flew through the Shuttle Landing Scenario

\begin{tabular}{|c|c|c|c|c|}
\hline Flight \# & $\begin{array}{l}\text { Aircraft } \\
\text { Type }\end{array}$ & Time Entered (Zulu) & Time Left (Zulu) & $\begin{array}{l}\text { Time in } \\
\text { SUA (min) }\end{array}$ \\
\hline JBU 1271 & A320 & $3: 46: 58 \mathrm{AM}$ & $3: 53: 58$ AM & 7 \\
\hline SWA 2455 & B737 & $3: 59: 58$ AM & 4:01:58 AM & 3 \\
\hline AAY 1717 & A320 & 4:03:58 AM & 4:11:58 AM & 8 \\
\hline JBU 1901 & A320 & $4: 10: 58$ AM & 4:19:58 AM & 9 \\
\hline EMJ 43 & F900 & $4: 15: 58$ AM & $4: 17: 58 \mathrm{AM}$ & 2 \\
\hline UAL 1082 & B738 & 4:18:58 AM & $4: 22: 58$ AM & 4 \\
\hline LN 990LC & LJ35 & $4: 20: 58$ AM & $4: 20: 58$ AM & 1 \\
\hline N472LX & BE40 & $4: 20: 58$ AM & $4: 24: 58$ AM & 4 \\
\hline JBU 705 & A320 & $4: 34: 58$ AM & 4:43:58 AM & 9 \\
\hline AAL 2206 & A319 & 5:02:58 AM & 5:03:58 AM & 1 \\
\hline BAW 242 & B744 & 5:58:58 AM & 5:58:58 AM & 1 \\
\hline \multirow[t]{2}{*}{ N400SC } & BE20 & $6: 41: 58 \mathrm{AM}$ & 6:56:58 AM & 17 \\
\hline & & & verage Time & 5.5 \\
\hline
\end{tabular}

We also examined air traffic across a 24-hour period based on our airspace closures for the shuttle landing (minus the corridor) to determine best time for landings based on air traffic. As illustrated in Figure 3, air traffic was most congested between 10:50-19:10 Zulu with approximately 175 aircraft at the high point and least congested between 00:30-07:45 Zulu. Thus, altering time of closures is but one variable in a basket of solutions that the FAA is considering. 


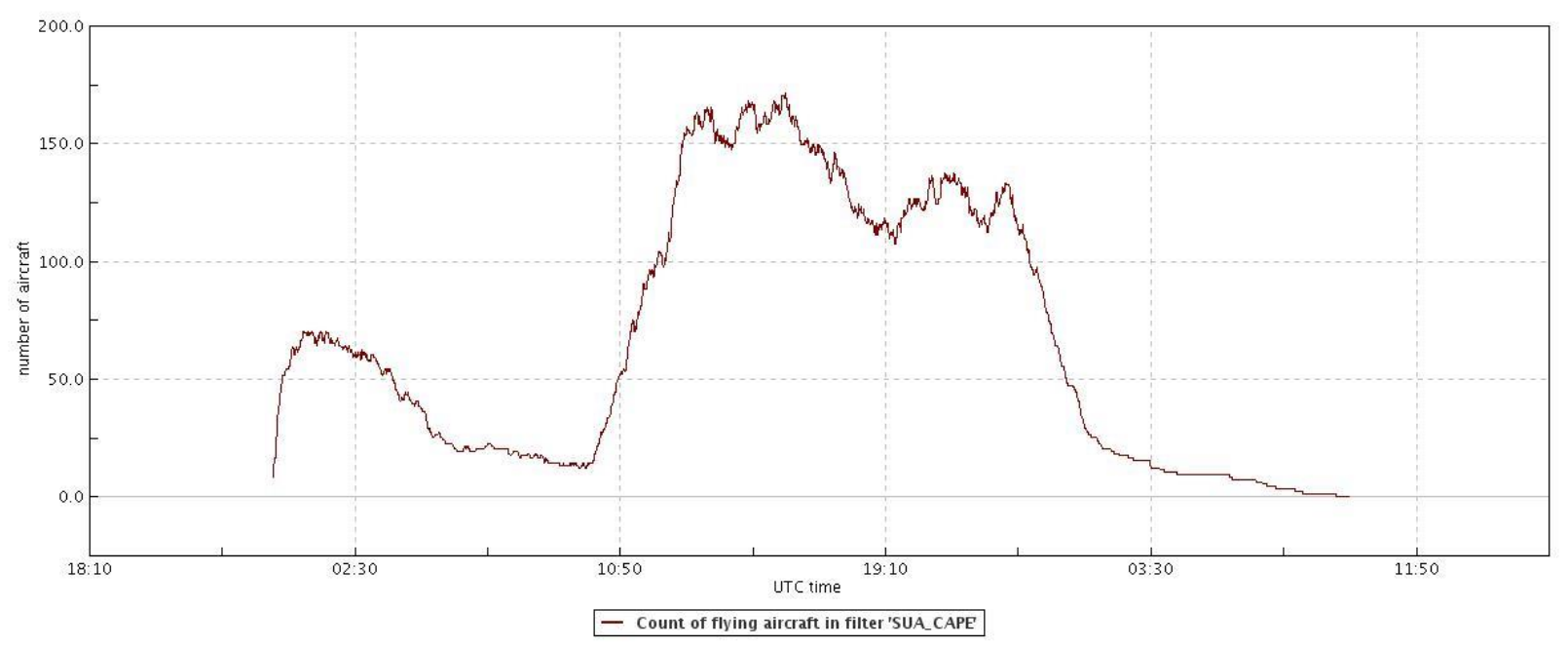

Figure 3. Count of aircraft flying through defined airspace closures over 24-hour period.

\section{Discussion and Recommendations}

We began our exploratory research endeavor by asking how many aircraft flights could be impacted by launch and re-entry activities at CCS, how many of these were domestic carriers versus international, and how many were GA. Based on our simulations for the time, date, and area of closures, impacts varied between 12 and 21 flights for our specific day of analysis and the type of space activity occurring. GA accounted for $33 \%$ of the impacted flights for the horizontal landing scenario, and both scenarios had international carrier impacts $(9.5 \%$ and $8.3 \%$ of launch versus horizontal landing, respectively). It follows that there is a potential cost associated with each impacted flight.

For any carrier, an airspace closure would likely trigger a flight plan change (reroute, altitude, etc.). Modifications to the original flight plan or air traffic control requested changes while the aircraft is enroute may subsequently result in additional fuel burn and flight delays, resulting in added costs to the carrier. Simulations performed by Tinoco et al. (2020) reveal added fuel and direct operating costs due to reroute ranged from $\$ 31,000$ to $\$ 55,000$ for one horizontal launch out of Cecil Air and Spaceport. These were primary effects only. When one 
carrier is rerouted, other carriers are likely rerouted to accommodate the original carrier's flight path modification. A ripple effect results with potentially astounding cumulative consequences to the industry.

While cooperative efforts continue between the federal government, the U.S. airlines, commercial launch providers, and the spaceports in determining the best approaches to airspace integration for safe operations, we found little research on impacts to international carriers.

When an international carrier is impacted by U.S. commercial space operations, there may also be political ramifications, further complicating an already complicated issue.

We discovered destination airports that could have been directly or indirectly impacted by delays, etc. included Orlando International Airport and Fort Lauderdale-Hollywood International Airport. Originating airports included Newark Liberty International Airport, LaGuardia and John F. Kennedy (JFK) in New York, among others. For horizontal landings with re-entry paths across the state of Florida (as shown in Figure 1), Tampa International could also be impacted, not to mention smaller GA airports.

For GA, the economic impact likely stems from business aviation, flight schools, FBOs, etc. that may be grounded by airspace closures. As noted earlier, five GA airports in the vicinity of CCS are impacted by closures due to launch. A review of the businesses located on-site or nearby that need airspace access include services for aviation training, aircraft maintenance, fueling and inspection, banner towing, air charter, air and biplane tours, and skydiving, among others. Informal interviews with personnel at the FAA further corroborated that detrimental consequences for GA are likely, but little has been studied with respect to this portion of the industry. Private pilots would also be impacted but to a lesser extent. 
One flight plan in our study listed Key West International Airport as the destination and Bradley International Airport in Connecticut as the flight origin, further highlighting the implications for smaller airports. As an aside, Florida is listed in the top four states for GA in terms of numbers of registered aircraft and GA public/private airports. GA contributed $7 \%$ to the Florida gross domestic product (GDP) and \$150 billion to the U.S. economy (AOPA, 2019).

In addition to launching during the time of least air traffic congestion, dynamically opening and closing airspace, based on rocket trajectory and non-anomaly situations, would be a solution, and this is already occurring in some limited situations. For example, with the last X37B landing at KSC, R2932, R2933, R2934, R2935 and several additional airspaces were closed at various times and for different lengths of time as the spaceplane flew through them. Also, from a regulatory standpoint treating spaceplanes, such as the Dream Chaser, as an aircraft would be a reasonable solution (Tinoco et al., 2019, 2020) if safety is not compromised. This would allow air traffic control to concentrate on reducing conflict with other aircraft in the area instead of creating hazard areas and closures. Although Dream Chaser is a glider, just as the space shuttle orbiter was, it is smaller in nature and may be more maneuverable.

Finally, it is recommended that the FAA continuously review all air traffic management processes and procedures for areas of improvement with respect to launch and landing operations and airspace restrictions. As more launches and re-entries occur using newer rocket and RLV technologies and capabilities, the more reliable the data to base 4-D airspace closures. As such, closures will shrink in time and space to the betterment of both sectors without sacrificing safety.

\section{Limitations and Conclusions}


Our exploratory research was limited in nature and scratches the surface of potential impacts. First, more simulations with a select sample of dates, time of day, and location will be critical in fully understanding impacts and finding generalizable solutions. Second, we were limited by the simulation software version in terms of creating restricted airspace scenarios with user defined SUAs and addressing aircraft fuel impacts and flight delays. These will be addressed in subsequent studies. However, we were able to analyze from a top-level perspective the best time of day for space operations to have minimal impact on aviation in our geographic area of interest. Future studies should cross-check how these "best times" aligned with the requirements of the various launches and landings studied. This was beyond the extent of the current study.

Our research, albeit focused in scope, is significant for carriers and GA, but also NASA, the FAA, the state of Florida, space industry, and the traveling public. We were able to examine, not only flights, but also origin and destination airports, opening a new area of research for us. Industry competition and structural pressures that inhibit the advancement of both the aviation and commercial space industries and their shared ecosystems are of concern. For both industries to economically thrive, there must be a balance of impact and an optimization of operations while maintaining safety as paramount. All stakeholders, industry, federal, state, and local, must be aware of and collaboratively work together to resolve these issues, remove roadblocks, and reap economic benefits. As our nation looks to further invest in space initiatives, examination of the positive and negative implications must be performed from all key stakeholder viewpoints to reduce risk and increase national return on investment.

\section{Acknowledgement}


This project was supported by the National Aeronautics \& Space Administration through the University of Central Florida's NASA FLORIDA SPACE GRANT CONSORTIUM. We would also like to acknowledge Embry-Riddle Aeronautical University for additional funding through student Spark Grants and the Faculty Research Development Program (FRDP); NASA for the use of NASA FACET simulation software, and Dr. Kapil Sheth, NASA Ames Research Center, San Jose, California for his enthusiastic support throughout this endeavor. 


\section{References}

Air Line Pilots Association (ALPA). (2018). Addressing the challenges to aviation from evolving space transportation. Retrieved from https://www.alpa.org/ /media/ALPA/Files/pdfs/news-events/white-papers/white-paperaviation-space.pdf

Air Line Pilots Association (ALPA). (2019). Safe integration of commercial space operations into the U.S. national airspace system and beyond. Retrieved from https://www.alpa.org//media/ALPA/Files/pdfs/news-events/white-papers/white-paper-aviation-space-followup.pdf?la=en

Aircraft Owners and Pilots Association (AOPA). (2019). State of general aviation. Retrieved from http://download.aopa.org/hr/Report_on_General_Aviation_Trends.pdf

Colvin, T. J., \& Alonso, J. J. (2015, August/September). Near-elimination of airspace disruption from commercial space traffic using compact envelopes. AIAA Space 2015 Conference and Exposition, Pasadena, CA. https://doi.org/10.2514/6.2015-4492

Federal Aviation Administration (FAA). (2015). CH-25 World Aeronautical Chart (WAC). 46 ${ }^{\text {th }}$ edition. Effective December 10, 2015 to December 8, 2016. Retrieved from https://aeronav.faa.gov/content/aeronav/wac_files/PDFs/CH-25_WAC_46_P.pdf

Federal Aviation Administration (FAA). (2019, June). Air traffic by the numbers. Retrieved from https://www.faa.gov/air_traffic/by_the_numbers/

Federal Aviation Administration (FAA). (2020). Commercial space data, active licenses. Retrieved from https://www.faa.gov/data_research/commercial_space_data/licenses/ 
Gebhardt, C. (2017, March 20). Air Force reveals plan for up to 48 launches per year from Cape Canaveral. Retrieved from https://www.nasaspaceflight.com/2017/03/air-force-reveals48-launches-year-cape/

Jacksonville Aviation Authority. (2014, October). Cecil Spaceport Launch Site Operator License (LSO 09-012) Renewal Application, Jacksonville, FL.

Jacksonville Air Traffic Control Center, Jacksonville Approach Control, Fleet Area Control and Surveillance Facility Jacksonville, and JAA Center, Miami Center, Jacksonville Approach Control, Cecil ATC Tower, Fleet Area Control and Surveillance Facility Jacksonville, and Jacksonville Aviation Authority/Cecil Spaceport Operations Office. (October 1, 2009). Letter of Agreement, Operations at the Cecil Spaceport at Cecil Field, Jacksonville, FL.

Larson, E., Carbon, S. L., \& Murray, D. L. (2012). Automated calculation of aircraft hazard areas from space vehicle accidents: Application to the shuttle. AIAA Atmospheric Flight Mechanics Conference and Exhibit, August 18-21, 2008, Honolulu, HI. https://doi.org/10.2514/6.2008-6889

Murray, D. (2008, August). Space and air traffic management of operational space vehicles. AIAA 2008-6890. AIAA Atmospheric Flight Mechanics Conference and Exhibit, August 18-21, 2008, Honolulu, HI. https://doi.org/10.2514/6.2008-6890

Murray, D., \& Mitchell, M. (2010, January). Lessons learned in operational space and air traffic management, AIAA 2010-1349. 48 ${ }^{\text {th }}$ AIAA Aerospace Sciences Meeting, January 4-7, 2010, Orlando, FL. https://doi.org/10.2514/6.2010-1349 
National Aeronautics and Space Administration (NASA). (2005, July). Airspace, bridges and waterway restrictions in effect for all space shuttle launches. Release 65-05. Retrieved from https://www.nasa.gov/centers/kennedy/news/releases/2005/65-05.html

National Aeronautics and Space Administration (NASA). (2020, May). Airspace, road, bridge and water closures for SpaceX Demo-2. Media Advisory M020-09. Retrieved from https://www.nasa.gov/press-release/airspace-road-bridge-and-water-closures-for-spacexdemo-2-0

Srivastava, A., St. Clair, T., \& Pan, G. (2018). On-demand assessment of air traffic impact of blocking airspace. The Aeronautical Journal, 122(1258), 1985-2009. https://doi.org/10.1017/aer.2018.105

Tinoco, J. K., Yu, C., Firmo, R., Castro, C. A., Moallemi, M., \& Babb, R. (2019, February). Sharing airspace: Simulation of commercial space launch impacts on airlines and finding solutions. Space Traffic Management Conference, Robert Strauss Center for International Security and Law, The University of Texas at Austin, Austin, TX.

Tinoco, J. K., Yu, C., Firmo, R., Castro, C. A., Moallemi, M., \& Babb, R. (2020). The impact of commercial space transportation on the United States National Airspace System (NAS) and airlines: A simulation model. Manuscript submitted for publication.

Tinoco, J. K., Yu, C., Howard, D., \& Stilwell, R. E. (2020a). Spaceport business and financial management. In An introduction to the spaceport industry: Runways to space. London, UK: Routledge. https://doi.org/10.4324/9781351165846-5

Tinoco, J. K., Yu, C., Howard, D., \& Stilwell, R. E. (2020b). Launch vehicles, propulsion Systems, and payloads. In An introduction to the spaceport industry: Runways to space. London, UK: Routledge. https://doi.org/10.4324/9781351165846-3 
Tinoco, J. K., Yu, C., Howard, D., \& Stilwell, R. E. (2020c). Spaceport infrastructure and operations. In An introduction to the spaceport industry: Runways to space. London, UK: Routledge. https://doi.org/10.4324/9781351165846-4

Young, J., \& Kee, M. (2014). SpaceX Falcon 9/Dragon operations NAS impact and operational analysis. DOT/FAA/TC-TN13/49. Washington, DC: U.S. Department of Transportation NextGen Implementation and Integration Office. Retrieved from http://www.tc.faa.gov/its/worldpac/techrpt/tctn13-49.pdf 